- Esse artigo faz parte da dis sertaçâo Ideologia e Poder no $P$ lanejamento Estratégico em Sad́de: uma discussão da abordagem de Mario Testa, apresentada d Ensp em 1989 para obtençäo do titulo de Mestrado em Saúde Pública. A dissertaçäo foi elaborada sob a orientaçäo do Prof. Adolfo Horacio Chorny.

** Pesquisadora-Assistente do Departamento de Administraçäo e Planejamento em Safude da Ensp/ Floctuz.

\section{As Origens e as Correntes Atuais do Enfoque Estratégico em Planejamento de Saúde na América Latina*}

\author{
Ligia Giovanella**
}

A partir de um breve historico do planejamento econômico e do planejamento em saúde na América Latina, a autora aponta três vertentes do enfoque estratégico do planejamento em saúde e suas origens: na discussão do planejamento para o desenvolvimento da América Latina, na administração estratégica empresarial e na discussão e critica do método Cendes/Opas.

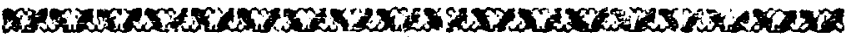

\section{BASES CONCEITUAIS E HISTÓRICAS DO} PLANEJAMENTO ECONÔMICO E SOCIAL

A noção mais simples de planejamento é a de não-improvisação. Uma ação planejada é uma ação não improvisada e, nesse sentido, fazer planos é coisa conhecida do homem desde que ele se descobriu com capacidade de pensar antes de agir, estando relacionado a todo processo de trabalho, e conseqüentemente, a toda vida humana, pois o trabalho é condição inerente à vida humana.

De forma mais abrangente enquanto cálculo de futuro - agir tendo como objetivo alcançar um fim determinado previamente - podemos considerar o planejamento como decorrência da calculabilidade e previsibilidade integrante da racionalidade concemente à sociedade capitalista moderna. Pensar o futuro e calcular a ação presente e futura para atingir uma finalidade - genericamente a maximização do rendimento em dinheiro - é o ethos da sociedade modema (Bourdieu, 1979). Calculabilidade e previsibilidade integram o sistema de disposiçōes em relação ao mundo e ao tempo concernente à nova racionalidade instituída com o desenvolvimento da sociedade industrial, passando a fazer parte da conduta razoável correspondente à razāo capitalista. Calculabilidade e previsibilidade presentes no cotidiano de todos: no interior da casa, nos cálculos de economia doméstica e no pensar o futuro dos filhos, na indústria, no comércio, na especulação financeira. 
$\mathrm{Na}$ sociedade tradicional - pré-capitalista - o que impera é a previdência: "pré-vidência", antevidência, um ver de antemão determinado pela tradição do sempre foi assim e assim será, como ciclos naturais que se repetem sempre da mesma forma. Nessa sociedade, a riqueza vem da natureza, a terra produz o valor. O trabalho vale em si e não valle pelo valor que produz: um homem digno é um homem sempre ocupado. O resultado do trabalho camponês, expressado na colheita, depende da natureza e não do próprio trabalho, da ação pensada, pois o futuro a Deus pertence. Pela tradição conserva-se o que é, a mudança não é cogitada. Previdência na sociedade tradicional tem o significado de um futuro imposto como o único possível.

$\mathrm{Na}$ sociedade moderna (capitalista), a previsão é resultado de um cálculo e pressupōe um outro futuro possível. O futuro não está predestinado, já não pertence a Deus, mas resulta da ação de homens e mulheres sobre a natureza. $\mathrm{O}$ valor - a riqueza - é produto do trabalho e o espírito de cálculo, objetivando maior produtividade e maiores ganhos, é exigência da própria economia capitalista (Bourdieu, 1979).

Com a industrialização os processos de trabalho complexizam-se, fragmentam-se, especializam-se e sua organização racional impōe-se. Cada indústria precisa tomar-se uma máquina bem azeitada e, cada vez mais, os processos de trabalho vão sendo organizados. É assim que as primeiras elaboraçōes teóricas mais sistematizadas sobre planejamento referem-se à organização da produção industrial nos primórdios da "administraçāo científica" quando, em 1916, Henry Fayol, ao editar o seu livro "Administração Industrial e Geral", coloca a previsão como um dos elementos da administração. Previsão é entendida aĺ enquanto projeção, cálculo de futuro, e a programação objetiva facilitar a utilização de recursos e a escolha dos melhores meios a empregar para atingir o objetivo desejado de máxima eficiência, máximo lucro.

$E$ enquanto função administrativa que o planejamento tem o seu desenvolvimento, e métodos e técnicas são elaborados. É no interior da empresa o seu locus. Inicialmente de maneira fechada e cada vez mais levando em consideração as flutuações do meio ambiente. Progressivamente complexizam-se seus procedimentos, chegando até a técnicas de projeção de diferentes cenários. Quanto mais complexo o que se planeja - o objeto do planejamento - maior número de variáveis a serem consideradas para o cálculo futuro. Impossível conhecer e controlar todas as variáveis $\mathrm{e}$, ainda que conhecidas todas as variáveis, diffcil estabelecer todas as relaçōes causais. Impossível esmiuçar completamente o presente, e o planejamento empresarial atual propõe-se, então, a diminuir esta variabi- 
lidade e pensar probabilidades de atingir-se os resultados desejados.

Calculabilidade e previsibilidade são parte também da ação consciente na construção da história futura. E, se já a própria revolução soviética resulta de um processo onde o cálculo e a previsão estão presentes - a possibilidade de um futuro diferente é afirmada -, após a revolução o planejamento vem dar racionalidade às transformações almejadas para toda a sociedade. E a primeira proposta de planejamento social surge na forma de um plano setorial na União das Repúblicas Socialistas Soviéticas quando, em 1918, é elaborado o primeiro Plano Nacional de Eletrificaçāo. Porém, somente após uma década de governo socialista, é elaborado o primeiro plano global: 1: Plano Qüinqüenal (1928 a 1932). Na sociedade socialista, com a instituição da propriedade social dos meios de produção, o plano vem para substituir o mercado como instrumento de alocação de recursos e distribuição de produtos e estabelecer justas proporçōes entre produção e consumo, oferta e demanda e entre os vários ramos da economia, com o propósito de satisfazer as necessidades de todos os membros dessas sociedades (Giordani, 1974).

Nas sociedades capitalistas baseadas nas "livres leis de mercado", no laissez faire, o planejamento econômico e social só é admitido após a crise econômica mundial dos anos 30 - profunda e prolongada depressão. Por essa época John M. Keynes, economista inglês, propōe uma maior intervenção do Estado na economia, com 0 intuito de diminuir a importância e freqüência das crises. Para Keynes é preciso dotar o Estado de instrumentos efetivos de política econômica que lhe permitam regular a taxa de juros, aumentar o consumo e expandir a inversão, visando o pleno emprego. Keynes propỏe maior dirigismo e racionalidade: propōe planejamento estatal (Keynes, 1978).

Suas formulaçōes são assumidas na Europa principalmente após o final da Segunda Guerra Mundial. Os primeiros planos são feitos em 1948 pelas naçōes européias participantes do Programa de Recuperação Européia ou Plano Marshall. Nessa ocasião, foram elaborados planos integrais para quatro anos, com o intuito de ordenar a produção e resolver a situação econômica e política nas zonas devastadas. Resolver a situação política e econômica era também a forma mais eficaz de contrapor-se ao avanço do mundo socialista emergente e presente no continente europeu após a partilha da segunda guerra (Giordani, 1974). 

MÉTODO CENDES/OPAS

$\mathrm{Na}$ América Latina, o planejamento é introduzido a partir da década de 40 , por influência da ONU e de um pensamento próprio que entende ser necessário superar as diferenças econômicas com os países capitalistas centrais. Aqui o planejamento é entendido enquanto instrumento para o desenvolvimento, e desenvolvimento significa crescimento do produto nacional, aceleração do ritmo deste crescimento. Desenvolvimento significa industrialização, modernização, e a racionalidade do cálculo econômico e do planejamento as acompanha.

E principalmente através da Comissão Econômica para a América Latina - Cepal - organismo internacional ligado a ONU, que se difunde a noção do planejamento enquanto necessidade para alcançar o desenvolvimento. Esta noção é baseada numa teoria que explica o subdesenvolvimento pela tendência à deteriorização dos termos de troca entre os países capitalistas centrais - economias industrializadas com produção diversificada e tecnicamente homogênea - e os países periféricos - economias exportadoras de alimentos e matérias-primas aos países centrais com produção muito especializada e tecnicamente heterogênea (Cardoso de Melo, 1984). Na noção difundida considerava-se que através do planejamento, poder-se-ia romper com essa tendência, promover a industrialização $\mathrm{e}$, através dela, alcançar o desenvolvimento.

O planejamento $e$, então, introduzido na América Latina enquanto método de seleção de alternativas que otimiza a relação entre objetivos e instrumentos com o propósito de crescimento, pois dentro das teorias desenvolvimentistas, entende-se ser o crescimento a solução para o subdesenvolvimento. Somente a aceleração do crescimento pode diminuir a distância com os países desenvolvidos: esta é a compreensão que caracteriza o planejamento da década de 50 (Matus, 1978).

A: propostas de planejamento na América Latina foram inicialmente elaboradas para a economia, mas, progressivamente, o campo de atuação para o planejamento é ampliado, sendo introduzido também nos setores sociais. $\mathrm{Na}$ saúde os primeiros programas surgem como decorrência da carta de Punta del Este. Em 1961 os EUA, através da Organização dos Estados Americanos - OEA -, promovem uma reunião de Ministros do Interior dos países das Américas, em Punta del Este, no Uruguai, onde é lançado o "Programa Aliança para o Progresso". Este programa é parte da política norte-americana do período Kennedy que colocava ên- 
fase nos obstáculos internos ao desenvolvimento (Cardoso, 1980). Considerava os problemas sociais e políticos como obstáculos internos ao desenvolvimento e entendia o subdesenvolvimento, pelos seus ingentes problemas sociais, como campo fértil para a proliferação de idéias alienígenas - socializantes. Com a "Aliança para o Progresso", através do financiamento de projetos sociais, pretendia-se contrapor à expansão dessas idéias, cujo exemplo de Cuba não se queria deixar reproduzir. A "Aliança para o Progresso" surge, portanto, como aliança para o desenvolvimento e contra o socialismo, com clara intenção de controle social.

$E$, pois, com essa intenção que, na reunião de Punta del Este, toma-se a decisão de incorporar os setores sociais à planificação do desenvolvimento. Metas sociais são acordadas entre países participantes, e o Banco Interamericano de Desenvolvimento e o Banco Mundial - Banco Internacional de Reconstrução e Desenvolvimento - sob a égide do FMI, são encarregados de financiar os projetos para o alcance dessas metas.

Para a área de saúde, a Carta estabelece objetivos e, por vezes, quantifica metas para o decênio próximo em relação a: taxas de mortalidade para certas idades e doenças preveníveis; saneamento e alimentaçäo; organização dos serviços de saúde; planejamento de saúde. Comprometem-se os países signatários da Carta a: reduzir a mortalidade de menores de 5 anos de idade; erradicar a malária e a varíola; intensificar o controle da tuberculose e das doenças entéricas; melhorar a alimentação e a nutrição aumentando a ingestão de proteínas; abastecer de água potável e serviços de esgoto pelo menos $70 \%$ da população urbana e $50 \%$ da população rural; melhorar a organização dos serviços de saúde e aumentar o seu rendimento, procurando que se atenda cada vez melhor um número maior de enfermos com atividades de prevenção e cura; ampliar a formação de profissionais e auxiliares em saúde; criar nos ministérios de Saúde unidades de planejamento integradas aos organismos de planejamento do desenvolvimento econômico e social; melhorar as estatísticas vitais e sanitárias; elaborar planos decenais nacionais de saúde; ter como meta geral o aumento de cinco anos na esperança de vida ao nascer de cada pessoa (OPS/OMS, 1971).

A Organização Pan-Americana de Saúde - Opas - fica encarregada de avaliar os projetos elaborados, objetivando o alcance dessas metas, e de ser a fiadora destes frente às agências financiadoras. Cabia ainda à Opas a função de assessorar os países na elaboração de seus planos e de promover a formulação de procedimentos para o planejamento de saúde, pois faltava um método para a elaboração dos planos. 
Até então, na Opas, trabalhava-se por objetos isolados e seus técnicos quase que desconheciam o planejamento, não havendo um método que permitisse formular planos globais de saúde e, por isso, Abraham Horwitz, diretor da Opas na época, logo após a reuniāo de Punta del Este, dirige-se a Caracas para contatos com Jorge Ahumada, diretor do Centro de Estudos do Desenvolvimento da Universidade Central da Venezuela - Cendes-UCV. Economista e professor de planejamento econômico, Jorge Ahumada dispōe-se a participar da elaboração de um método de planejamento de saúde e sugere que, para tal, seja tomado como base um trabalho realizado por Mario Testa, quando aluno do mestrado de planejamento econômico no Cendes. Ahumada estivera interessado em saber se o método de planificação econômica podia ser aplicado a uma área social e por isso solicitara a Mario Testa, que era médico, que realizasse um trabalho nesse sentido. O diretor da Opas aceita a sugestão, sendo então formada uma equipe de trabalho para a elaboração de um método de planejamento de saúde. Dessa equipe participaram o próprio Ahumada e Mario Testa pelo Cendes, Alfredo Arreaza Guzmán, médico sanitarista venezuelano da Escuela de Salud Pública, Mario Pizzi, médico chileno dedicado à estatística de saúde e integrante do Ministerio de Sanidad y Asistencia Social, e, pela Opas, Eduardo Sarué, também dedicado à estatística médica, e Hernán Durán, sanitarista.

Tomando como base o trabalho de Testa e o modelo do planejamento econômico, esta equipe elaborou o método de planejamento em saúde que ficou conhecido como "método Cendes/Opas". Este método foi editado pela Opas, em 1965, na sua Publicação Científica número 111, sob o título: Problemas Conceptuales y Metodológicos de la Programación de la Salud (OPS/OMS, 1965).

Para a elaboração do método Cendes/Opas é realizada uma transposição rígida do planejamento econômico normativo, de linha cepalina, para a saúde, resultando num método de planejamento de saúde onde a realidade deve funcionar enquanto norma e cujo objetivo é otimizar os ganhos econômicos obtidos com saúde e/ou diminuir os custos da atenção, sendo a escolha de prioridades feita a partir da relação custo/ benefficio. Nesse método, a formulação do plano é iniciada com a realização de um diagnóstico: dos planos e de seus condicionantes, dos recursos, com sua forma de organização (instrumentação) e rendimento correspondente, e da alocação dos recursos aos danos. A partir desse diagnóstico, é feita uma seleção de prioridades e proposta uma nova organização de recursos, relacionando-se então os instrumentos normali- 
* Instrumento $\varepsilon$ um conjunto heterogeneo de recursos utilizados na realizaçăo de uma tarefa $e$ combinados proporcionalmente entre si segundo critérios de effcacia e eficiencia, Tarefa $E$ todo conjunto de acóes seqūenciais realizadas para alcançar um objetivo definido e mensurável. Como exemplo de uma tarefa temos a hospitalização, cujo instrumento denominase leito hospitalar. A técnica é o conjunto de tarefas realizadas para o ataque a um dano, por exemplo: vacinaçăo + tratamento ambulatorial + hospitalizaçáo constituem a técnica de ataque \& uma doença qualquer. zados aos danos priorizados, com o intuito de alcançar maior eficácia e eficiência nas açōes de saúde.

Esta é uma proposta tecnocrática, onde o planejador, baseado em seus conhecimentos técnịcos "neutros", faz o plano e estabelece prioridades. E um método normativo e economicista, onde a norma - o deve ser - tem como fundamento principal a relação custobeneflicio.

No texto de apresentação do método Cendes/ Opas, inicialmente, propōe-se a elaboração de um método baseado nos anos de capacidade produtiva perdi$d a$. Idéia que os autores dizem ser abandonada pelas dificuldades de cálculo e falta de dados disponíveis. Propōe-se pensar a capacidade potencial produtiva o número de anos/pessoa que dispōe uma comunidade, utilizável em qualquer tipo de atividade - a partir da determinação da esperança de vida para cada idade. A idéia era verificar quantos anos/meses de capacidade produtiva eram perdidos quando uma pessoa ficava doente ou morria em tal ou qual idade. Não se esquecendo de verificar os recursos gastos pela sociedade na formaçảo da pessoa. Nessa concepçấo, se uma pessoa morre, por exemplo, aos dezoito anos, tem-se uma perda maior do que com uma que morra aos 5 anos de idade, pois a quantidade perdida de anos de capacidade produtiva potencial $\varepsilon$ quase igual, mas os recursos sociais investidos não. No jovem, a sociedade investiu, por 18 anos, recursos para a sua formação, e ele mal começou a produzir. Essa idéia de anos de capacidade produtiva perdidos orienta o método, porém, não são apresentados procedimentos para seu cálculo pela dificuldade/impossibilidade que apresenta.

A norma geral para determinar a alocação de recursos nesse método é a obtençâo de máxima produtividade, máxima eficiência: um máximo de produto por unidade de recurso empregado, e o problema na programação em saúde consiste então em como melhor empregar os recursos, ano por ano, para conhecer os distintos danos de forma mais eficiente. Para isso, o procedimento mais importante $\varepsilon$ a determinação de quanto se gasta, no total, no ataque a cada um dos danos e qual o custo por morte evitada e por caso reparado. Análise que, por ser complexa, deve ser feita apenas para os danos principais, selecionados a partir dos critérios de "magnitude", "transparência" $\mathrm{e}$ "vulnerabilidade" aplicados às causas de morte.

Para o cálculo do custo unitário do ataque a cada dano, realiza-se inicialmente um inventário dos recursos disponíveis e das ações realizadas. Os recursos inventariados são relacionados aos seus usos através da sua agrupação em instrumentos, tarefas e técnicas* 
Analisada a composição dos instrumentos e seu rendimento esses são comparados com uma norma para a composição, grau de utilização e rendimento, identificando-se possíveis deficiências de instrumentalização, baixo rendimento etc. Desse modo são normalizados instrumentos e tarefas e são estabelecidas metas de rendimento, tendo-se um modelo normalizado da organização dos recursos.

Conhecendo-se a composição do instrumento em termos de recursos, o custo da unidade dos recursos e o tipo e número de tarefas e técnicas utilizadas, pode-se calcular quanto custa o ataque a cada dano, qual o custo por morte evitada.

Conclue-se a eleição de prioridades pela ordenaçāo dos danos, analisados segundo os custos, de forma crescente, sendo considerado prioritário o dano cujo custo para evitar uma morte é o menor. Alocam-se então os recursos (instrumentos e técnicas normalizados) ao dano prioritário, até alcançar-se a taxa de mortalidade que permita essa técnica mais eficiente, passando-se subseqüentemente para os danos de menor prioridade. Como existem doenças não-redutíveis, cuja vulnerabilidade zero as exclue das prioridades, sugerese separar recursos para sua atenção, pois considera-se esta demanda uma exigência da comunidade.

Esses são, em sintese, os conteúdos principais do método Cendes/Opas. Para a divulgação do método, já antes de sua publicação, a Opas promoveu em conjunto com o Ilpes (Instituto Latino Americano de Planificação Econômica e Social) a capacitação de funcionários de órgãos de saúde na utilizaçảo do novo método, através da realização de cursos em vários países como Venezuela, Chile, Colômbia, Argentina e, já a partir de 1963, sistemas de planejamento em saúde começaram a funcionar. Em 1968 foi criado - Centro Pan-Americano de Planificação de Saúde, que passou a funcionar junto ao Ilpes, em Santiago. Esse centro, que funcionou até 1975, intensificou a capacitação de "funcionários de alto nível" e divulgou amplamente o método.

A idéia de que a formulação de planos nacionais era um pré-requisito para obtençāo de financiamentos perdeu força à medida que a expectativa de cooperaçäo externa, através da "Aliança para o Progresso", também se diluíra (OPS/CPPS, 1975). Mas a idéia do planejamento vingou, e muitos países passaram então a fazer planos de saúde utilizando, em sua estrutura básica, o método Cendes/Opas. Cada país apresentando, porém, peculiaridades nos seus sistemas de planejamento e na aplicação do método.

Quando os paises começaram a fazer planos, começaram também a aparecer problemas que o método nâo resolvia, o que levou à incorporação de algumas

Cadernos de Safide Pública, RJ, 7(1): 26-44, jan/mar, 1991. 
modificaçōes ao método. Uma delas foi a inclusão do diagnóstico institucional, passando-se a considerar diferentes instituiçōes prestadoras de serviços, pois no método inicial isto năo ocorria. Propunham-se apenas divisões por regiōes e áreas como se existisse um sistema único de saúde. Outra incorporação foi a da "política" como um fator interferente para a realizaçấo dos planos, passando-se a considerar a importância de aumentar as propostas governamentais.

Por vários anos o método foi desse modo difundido e, ainda que sofrendo críticas, tentativas para sua aplicação foram feitas. Já no final dos 60 há descontentamento dos planejadores com o método pelas dificuldades para a sua aplicação, porque políticos e administradores não seguiam os planos elaborados. No método Cendes/Opas, por ser um método normativo, - mesmo após a incorporação da política enquanto um fator - considera-se que apenas um ator planeja com plenos poderes, supondo sempre o consenso ou o quase-consenso. Desconsideram-se conflitos e diferentes interesses. Desconsidera-se a existência de interesses contraditórios quanto à saúde e sua atenção, como se houvesse uma decisão política, $a$ priori, favorável ao emprego mais racional dos recursos visando a maior eficiência. Estando, então, o técnico-planejador encarregado de implementar esta decisão. O planejador é entendido como um técnico a serviço do político. Acontece, porém, que essa decisão não existe a priori. A realidade não se limita ao "deve ser" da norma. A situação é de conflito e disputa pelo poder e não de consenso, e a política implantada é o resultado de todo um conjunto de disputas e acordos.

Os planos elaborados pelo método Cendes/Opas, cujo suposto objetivo seria operacionalizar a decisão governamental de maior racionalidade numa situação de consenso, não são executados, pois não existe essa decisão e a situação não é de consenso. Ao não considerarem a variabilidade e complexidade da realidade, os conflitos e os diferentes interesses não dão conta dessa realidade, tomando-se pouco úteis para a intervençăo. Tornam-se, apenas, livros-planos adormecidos no interior das gavetas. O método cai, então, em descrédito e, já em 1973, a própria Opas em sua Publicação Científica n: 272 , assume o fracasso do método.

Pode-se dizer que atualmente o Cendes/Opas enquanto um método de programação como um todo não é mais utilizado, porém, como resultado da sua ampla divulgaçāo, alguns de seus componentes ainda permanecem e, se não são aplicados, pelo menos ainda continuam sendo ensinados em variados cursos. Um exemplo do que ficou é a eleição de prioridades baseada nos critérios de magnitude, transcendência e vulnerabilidade, assumindo-se, assim, ainda, uma visão tecc- 
nocrática da programação de saúde. Tecnocrático tem aqui o sentido literal do termo: o poder da técnica na definição de prioridades. Quer dizer, a partir de um conhecimento técnico e da avaliação que é feita, também pelo técnico, da importância de um determinado grupo social, são definidas prioridades.

Por outro lado, também considero que alguns aspectos do método continuam atuais para a programaçāo de saúde, pela sua adequação enquanto procedimentos para uma análise e cálculo de recursos. É o caso da definiçāo do instrumento e análise de sua composição (a organização dos heterogêneos recursos necessários à realização de uma tarefa), da análise do rendimento e grau de utilização dos instrumentos, da quantificação de tarefas realizadas, da comparação desse observado com algum parâmetro normativo.

A época, o descrédito do método Cendes/Opas não advém apenas de problemas internos ao método, - não está em questão apenas um método de planejamento de saúde - o que está em discussāo são as próprias teorias desenvolvimentistas orientadoras das propostas de planejamento como instrumento para a superação do subdesenvolvimento. Para o planejamento econômico, já na metade dos anos 60 , questionamentos começam a ser feitos, pois verifica-se que um maior ritmo de desenvolvimento alcançadu num país não fazia esse menos dependente nem levava à solução dos problemas diagnosticados, como, por exemplo, a concentração de renda e o desemprego. Perguntas como: Qual a direção do desenvolvimento? Aceleração até aonde? são realizadas. Pensar na direção significa mudar os processos em curso. Mudar os processos significa pensar no político, pensar uma estrutura de relaçōes de poder, um sistema de decisōes, um padräo de relações com o exterior, uma definição das relações sociais de produção que caracteriza a sociedade que se pretende construir (Matus, 1978). O político precisa, entāo, ser incorporado ao planejamento naao mais como um fator, mas como objeto do planejamento. Começam af as formulaçōes de planejamento estratégico.

Carlos Matus, então diretor do Serviço de Assessoria do Instituto Latino-Americano de Planificaçăo Econômica e Social - Ipes - partilha desses questionamentos escrevendo, em 1968, Estrategia y Plan, texto publicado em 1972. Nesse trabalho Matus assume que a direcionalidade do desenvolvimento deve ser a mudança de estruturas e sugere um rumo para a abordagem dos grandes problemas enfrentados pelo planejamento, propondo a formulação de estratégias de desenvolvimento que apresentem a coerência necessária entre eficácia econômica e eficácia política. 
Já nesse texto, Matus diferencia entre procedimentos normativos e procedimentos estratégicos. Pelo procedimento normativo define-se um conjunto de açōes necessárias para cumprir um objetivo fixado $a$ priori, impondo-se sobre a realidade uma norma de conduta coerente com os objetivos. Nesse procedimento a trajetória entre a situação inicial e o objetivo é uma trajetória eficaz que deve substituir o comportamento real. O procedimento estratégico pressupōe respostas do sistema às açōes para sua alteração, e a norma é o ponto para o qual se quer encaminhar o funcionamento do sistema. A trajetória é flexível, sujeita a revisōes de acordo com as circunstâncias, e a busca da modificação do sistema baseia-se no conhecimento da realidade e não numa imposição sobre a realidade.

A norma, fundamento do procedimento normativo, diz Matus, é uma categoria do necessário e a estratégia é uma categoria do possível em função do necessấrio. $\mathrm{Na}$ estratégia a condução do processo não está dissociada da sua orientação (Matus, 1978).

A estratégia, para Matus, é uma análise e um propósito para o futuro, onde se integram o econômico e o político social. O necessário é conflitivo, diz ele, e a consideração do conflito, contradições, oposições, acordos - a análise de viabilidade política - diferenciam entre o procedimento estratégico e o normativo. Propōe a construção de um modelo que funcione como a realidade, reagindo e dando respostas a simulaçōes/ ensaios de fatos e perturbaçōes. Um modelo que possa permitir a dedução de uma política viável, capaz de aproximar-se dos objetivos perseguidos.

Essa discussão com alguma defasagem de tempo atinge também a área da saúde. As críticas às teorias desenvolvimentistas e ao planejamento econômico, decorrentes da situação político-econômica dos países latino-americanos, somadas a problemas intemos ao método Cendes/Opas, produzem o descrédito desse método.

Contribuem também para esse descrédito as propostas de extensão de cobertura dos serviços de saúde surgidas no início dos anos 70 . Na terceira Reunião Especial de Ministros de Saúde das Américas, realizada em 1972, propõe-se a extensão dos serviços de saúde para populaçóes urbanas e rurais até então desassistidas (OPS/OMS, 1975). O método Cendes/Opas não tem resposta a essa proposta, pois, a análise da capacidade instalada, sua expansão e tecnologia não são suficientemente elaboradas para tal.

Em 1973 é escrito pelo Centro Panamericano de Planificación de la Salud o documento Formulación de Políticas de Salud. Nesse documento as relações entre as forças sociais, os conflitos e a viabilidade 
do planejado são abordadas. A análise de viabilidade passa a şer parte integrante do processo de planejamento. E entendida enquanto possibilidade política do plano ser executado sendo, então, considerados possíveis aliados e oponenteș. Para a análise de viabilidade, são estudadas quais oposiçōes surgirão ao plano e as formas de reagir frente a estas e quais acordos serão necessários para alcançar a execução do plano.

Neste documento, estratégia tem o sentido da seleçāo de meios, intensidade e oportunidades de ação e discussão, que exige a dialética das vontades enfrentadas (OPS/CPPS, 1975). O planejamento é situado no campo das decisões políticas. A análise da política - dos processos que conduzem à tomada e execução de decisōes - é considerada fundamental para o planejamento.

Para Uribe, o documento apresenta uma contradição básica: o conflito assumido no marco in terpretativo do processo político desaparece no esquema apresentado para a formulação de políticas ... de maneira que este processo reduz-se a uma seqüencia de etapas em que se afirma a vontade da autoridade politica (qualquer uma). O conflito só reaparece na análise de viabilidade (elaboraçāo da estratégia) quando se trata, não de modificar substancialmente as proposiçöes polfticas já assumidas, mas de ordená-las e dosá-las em conformidade com o estudo das reações sociais...(Uribe, 1982).

A principal contribuição do documento é a proposição da análise de viabilidade, introduzindo a questão da estratégia no planejamento de saúde. Ainda que seja uma crítica ao planejamento de saúde realizado até então, o documento apresenta uma visão funcionalista do que acontece na realidade. Nesse documento propöe-se certa normatividade da política, uma operacionalização tecnocrática da problemática da política. Sugere-se uma série de passos para a operacionalização do político, estabelecendo um "deve ser" da política ao nível das funções, onde o conflito advém da posse desigual de bens pelos diferentes grupos sociais, não se discutindo as determinações dessa posse desigual e não sendo colocadas as contradiçōes e interesses antagônicos fundadores da sociedade de classes que é o capitalismo.

Mesmo assim, o documento Formulación de Poltticas de Salud, publicado em 1975 pelo Centro Panamericano de Planificación de la Salud, tem sua distribuição restringida/proibida pela Opas que não assume - seu conteúdo “mais político". Essa é a época em que o avanço significativo do movimento popular, em vários países da América Latina, é sufocado por golpes militares com a imposição de ditaduras, com o apoio norte-americano, em todo o cone sul (Testa, 1985).

Cadernos de Saúde Pública, RJ, 7(1): 26-44, jan/mar, 1991. 
Com a derrota dos movimentos populares e a implantação das ditaduras militares, muitos dos profissionais e teóricos do planejamento são afastados dos níveis de in tervenção e vão reinserir-se em outros países, geralmente em instâncias acadêmicas, onde se dedicam a uma reflexão sobre as suas atuaçōes e sobre o fracasso dos movimentos dos quais participaram.

\section{AS TRÊS VERTENTES DO} ENFOQUE ESTRATÉGICO

\section{O Planejamento Situacional}

Carlos Matus, ex-ministro do governo socialista de Allende no Chile, faz essa reflexão inicialmente nos cárceres de Pinochet $\mathrm{e}$, depois, em seu exílio na Venezuela, como assessor das Naçōes Unidas (llpes e PNDU) e do Cendes. Mario Testa, que, após trabaIhar no Cendes desenvolvendo o método Cendes-Opas e na divisão de pesquisa do CPPS, deslocara seus interesses para os movimentos populares que ocorriam na Argentina, atuando no movimento peronista, faz essa reflexão no exílio. A temática de Testa e Matus é a mesma. Motivados pelo fracasso dos movimentos populares, ambos discutem a questão do poder.

Matus aprofunda a sua discussão iniciada no $E s$ tratégia y Plan fazendo uma análise globalizante do planejamento na economia. Inicialmente, enfatiza a discussão sobre o poder e tenta desenvolver um rigoroso método de planejamento. Atualmente, porém, está mais preocupado com a construção/elaboração de instrumentos de condução que aumentem a governabilidade de um sistema político.

Propõe um método de planejamento situacional onde o ator que planifica está dentro da realidade e coexiste com outros atores que também planificam, diferente do método normativo, onde o planejador é um sujeito separado da realidade, colocando-se fora dela e pretendendo controlá-la como se fosse seu objeto. Situação é o lugar onde estão os atores e suas açōes. É a explicaçấo da realidade que realiza uma força social em função de sua ação e luta com outras forças sociais (Matus, 1982).

Nessa concepção, a contradição e o conflito são assumidos e a planificação situacional, diz Matus, $\varepsilon$ necessariamente política, pois um dos recursos escassos que restringem o desenvolvimento de ações que promovam mudanças são os recursos de poder.

Planejamento situacional é um método de planejamento constituído por quatro momentos não-seqüenciais, simultâneos e em constante processo. Um momento explicativo equivalente ao diagnóstico onde são selecionados problemas e discutidas suas causas ao 
nível dos fenômenos (fenoestrutura) e das estruturas sociais básicas (genoestrutura). Um momento normativo: o desenho do "deve-ser". Um momento estratégico de análise e construção da viabilidade política: a discussão do poder. Um momento tático-operacional de tomadas de decisão e de realização da ação concreta.

Por refletir sua própria experiência, $o$ ator privilegiado é o goyerno. Planejar, para Matus, é conduzir o processo. E tentar submeter à vontade humana o curso encadeado dos acontecimentos cotidianos, fixando uma direção e dando uma velocidade à mudança que inevitavemente acontece. É método de conduçấo do governo para o alcance de seus objetivos. Planeja quem governa: quem tem a capacidade de decidir e a responsabilidade de conduzir (Matus, 1981).

O fracasso do planejamento é também fracasso da condução. Uma das razóes que Matus detecta para esse fracasso $\hat{\varepsilon}$ a falta de instrumentos, procedimentos e técnicas de conduçāo e, por isso, coloca aí sua ênfase, desenvolvendo instrumentos para que aquele que tenha responsabilidade da conduçấo consiga exercê-la. Preocupa-se então em dotar o governo com elementos técnicos que aumentem a governabilidade do sistema (procedimentos para lidar com a incerteza, sala de situaçōes....).

O planejamento situacional é uma evolução do pensamento crítico dos anos sessenta em relação ao planejamento econômico. Pode ser considerado como uma vertente do planejamento estratégico de saúde, pois o pensamento de Matus, pelo seu frequente trabalho como assessor da Opas, tem sofrido adaptaçōes para a saúde. Essas, mesmo que nem sempre bem sucedidas, têm influenciado atuaçōes de planejamento em saúde.

\section{As Propostas Programático-Estratégicas}

Mario Testa, em sua reflexão e autocrítica, por sua participação na política, pensa o problema do Poder como problema central do planejamento de saúde. Sua reflexão á como participante de um movimento social desde fora do governo. Seu ator privilegiado é, então, a classe/grupo/força social/movimento, e não, como em Matus, o governo. Refere toda a sua proposta à luta pelo poder: como conduzir deslocamentos de poder em favor das classes/grupos subordinados/dominados.

Ao considerar a determinação social do processo saúde-enfermidade, identifica os problemas de saúde como integrantes da totalidade social, fazendo a ligação saúde-totalidade social através das relaçōes de poder. Propōe um diagnóstico da situação, cuja síntese é a identificação do setor enquanto a estrutura do 
poder: relaçōes entre forças sociais com interesses em saúde e as tensões decorrentes do debate em saúde. Síntese realizada a partir da consideração do cálculo administrativo tradicional (diagnóstico administrativo); das relações de poder e suas determinações na sociedade (diagnóstico estratégico) e das formas de consciência social e sanitária (o diagnóstico ideológico) (Testa, 1986).

Baseado na síntese diagnóstica, onde foi identificada a estrutura de poder setorial, formula propostas programático-estratégicas que consideram a análise das repercussōes das ações propostas sobre essa estrutura de poder. $\mathrm{Na}$ seqüência de programas sugerida, Testa considera a criação e a manutenção da viabilidade política que garantam a realização e consolidação das mudanças propostas. Programas cujo conteúdo estratégico são suas formas organizativas democráticas e participativas, pois, segundo Testa, estas estabelecem diferentes formas de relações de poder, dando direcionalidade às suas proposições (Testa, 1987).

Mario Testa apresenta um quadro de análise para se pensar as questồes do planejamento. Suas proposiçōes setoriais são acompanhadas de toda uma discussão do Poder na sociedade, suas determinações e possibilidades de transformação. A preocupação de Testa com - setor é subsidiária à sua preocupação com o Poder como um todo, configurando à sua produção um quadro de análise/um corpo de teoria, a partir do qual pensar o planejamento.

\section{A proposta de Medellin}

Uma terceira linha do planejamento estratégico de saúde desenvolve-se a partir de uma reflexão promovida no interior dos próprios organismos internacionais (OPS/OMS), dando uma certa continuidade a questōes colocadas no documento Formulación de Políticas. Essa vertente $e^{\prime}$ apresentada inicialmente nas Notas sobre las Implicaciones de la Meta SPT/2000, la Estrategia de Atención Primaria y los Objectivos Regionales Acordados para la Planificación y Administración de los Sistemas de Servicios de Salud, um documento borrador da Opas, de circulação restrita, elaborado a partir de debates em seminários internacionais com especialistas em planejamento - Medellin, Mérida e Rio de Janeiro - e de um curso realizado na Facultad Nacional de Salud Pública de Medellin. Em 1987, esse documento é editado como Salud para Todos en el Año 2000: Implicaciones para la Planificación y Administración de los Sistemas de Salud, tendo como autores Emiro Trujillo Uribe e Juan José Barrenechea (Barrenechea \& Trujillo, 1987). Trujillo, inicialmente aluno e depois consultor do Centro Panamericano de 
Planificación de la Salud até sua extinção em 1975, foi diretor e professor de Planejamento na Escola de Saúde Pública de Medellin, na Colômbia, até 1988, quando foi assassinado. Barrenechea foi participante de Cursos de Planejamento e Desenvolvimento Econômico na Cepal e Ilpes e trabalhou em planejamento na Opas, de 1966 até 1980.

O texto de Trujillo e Barrenechea mantém-se como notas sobre planejamento e administraçāo de sistemas de saúde, nẫo pretendendo os autores a proposição de um método de planejamento.

Por suas origens, nas discussões nos seminários, o texto tem contribuiçōes de vários autores: Matus e Testa, por exemplo, fazem parte de sua bibliografia de referência. Mesmo assim, apresenta uma especificidade em sua orientação. Sua racionalidade basicamente sustenta proposições do planejamento estratégico empresarial e, por isso, considero-o uma terceira vertente.

O planejamento estratégico e depois a administração estratégica, desenvolvidos para as grandes empresas desde o final dos anos 60 , diferem do planejamento normativo tradicional. Admitem a turbulência do ambiente externo e tratam de como as empresas devem orientar-se no processo de adaptação ao ambiente. O comportamento estratégico é considerado como um processo de interaçāo com o ambiente, acompanhado de um processo de promoção da modificaçâo de aspectos dinâmicos internos, onde a turbulência extema e o poder configuram-se como influências básicas (Ansoff, 1983). Essas concepçōes permeiam o texto de Barrenechea e Trujillo, influenciando na origem dessa "vertente" do planejamento estratégico de saúde.

O interesse desses autores $\varepsilon$ o setor saúde e sua preocupação principal a instrumentalização: como fornecer instrumentos que auxiliem técnicos atuantes na linha de execução, que rompam com o normativo e contribuam na implementação das Estratégias SPT2000. Propōem uma metodologia de planejamento para ser utilizada por qualquer força social que assuma a meta SPT2000 e a estratégia de atenção primária.

Nesse enfoque, o planejamento $\varepsilon$ entendido como um processo scicial complexo, que trata de influenciar as características de uma mudança social a partir da perspectiva de uma determinada força social. Pressupöe-se que, para pensar a ação futura, é necessário conhecer-se uma teoria política, mas esta teoria não é explicitada nem discutida. Assim, a existência de interesses conflitivos é reconhecida, porém a determinação desses conflitos não é colocada. Diferenças entre grupos sociais quanto ao acesso aos serviços e aos riscos de agravo à saúde são constatados, sem também 


\footnotetext{
* "Estratégia" e "Tática" são ter* mos interligados, produzindo-se por vezes confusóes entre seus significados. A tática subordinase à estratégia. Tática é um meio de aplicação da estratégia. É parte da guerra que trata da arte de manobrar as tropas durante o combate. Arte de utilizar as armas em combate, tirando de las o maior rendimento.
}

explicitar-se a determinação dessas desigualdades. Evidenciadas as diferenças, os instrumentos elaborados para a intervenção no setor saúde direcionam-se aos grupos sociais chamados de "postergados" objetivando diminuir essas desigualdades.

Barrenechea e Trujillo admitem: a complexidade do sistema de saúde como parte integrante do social, pois o ambiente social é turbulento e pouco previsível; a fragmentação (o desenvolvimento dos processos sociais de forma brusca e não-linear); a dependência do sistema de variáveis fora de seu domínio, fora de seu espaço de controle; e a incerteza no tratar com o futuro. Admitem, ainda, a existência de forças em oposição, a necessidade da negociação e de procedimentos para tal, e colocam o plano como algo em permanente elaboração e execuçấo, quebrando, em diversos níveis, a base do planejamento normativo tradicional (Barrenechea \& Trujillo, 1987).

\section{CONCLUSÕES}

Identificamos, assim, três vertentes de planejamento estratégico em saúde atualmente em difusão na América Latina: o planejamento situacional de Matus aplicado à saúde, as propostas de Mario Testa e o enfoque de Barrenechea e Trujillo.

Cabe, certamente, um esclarecimento sobre o sentido aqui empregado para a estratégia, pois é um termo amplamente utilizado, apresentando múltiplos significados. Estratégia é arte de explorar condições favoráveis com o fim de alcançar objetiyos específicos. É meio para alcançar um objetivo. É proposição para futuro: o enunciado de diretrizes para o longo prazo (significado que aparece, por exemplo, em documentos das Nações Unidas). É proposta para ganhar um jogo. $\hat{E}$ arte de ganhar a guerra.

$\mathrm{Na}$ sua origem castrense, estratégia é arte de dirigir operações militares (OPS/CPPS, 1975). Arte militar de planejar e executar movimentos e operaçōes de tropas e veículos de guerra, visando alcançar ou manter posiçōes favoráveis a futuras açōes sobre determinados objetivos; programação a longo prazo do uso de instrumentos militares e políticos na condução de conflitos (Bobbio et all, 1986).

Por sua origem militar, geralmente incorpora-se o termo "estratégia" a situações em que, para alcançar um objetivo, é necessário superar obstáculos: quando existem oponentes ao alcance de um objetivo, e para alcançá-lo, é necessário vencer a resistência dos oponentes.* O termo 'estratégia' é, portanto, empregado quando existe conflito, enfrentamento, relação de poder, e este é o caso do planejamento de saúde.

O sentido militar do termo, em suas elaboraçoes mais acabadas, é teoria de movimento até o objetivo,

Cadernos de Sáde Páblica, RJ, 7(1): 26-44, jan/mar, 1991. 
buscando-se obter o máximo de libęrdade de ação após cada movimento (Matus, 1982). E este o sentido de estratégia quando falamos aqui de planejamento estratégico. Sem esquecer que, no conflito entre forças sociais, como bem diz Matus, o que acontece é um jogo dialético, pois as forças sociais têm uma história e constituem uma unidade contraditória. Nesse, como em qualquer outro jogo, enfrentam-se oponentes que, para ganhar, têm de vencer a resistência dos outros; porém, no jogo dialético, um jogador não existe sem o outro. O jogo dialético supõe a unidade e a contradição entre as forças sociais.

É com esse sentido que afirmamos os enfoques de planejamento de saúde aqui apresentados como estratégicos, pois consideram o problema do poder $\mathrm{e}$ admitem o conflito entre forças sociais com diferentes interesses e com uma visão particular sobre a situação-problema na qual se planeja, fazendo parte do processo de planejamento a análise e a construção da viabilidade. E porque os processos de planejamento propostos objetivam alcançar o máximo de liberdade de ação a cada ação realizada, movimento que possibilita a aproximaçã̃o dos propósitos desejados.

As três vertentes tểm em comum a ação estratégica e sua ruptura com a normatividade de um "deve ser" que se impöe sobre a realidade, admitindo a impossibilidade de contar-se com um plano pré-estabelecido que dê conta de todas as condiçōes do real, devido à complexidade dos processos sociais. Cada uma, porém, apresenta um enfoque específico, com diferente ênfase. Matus dá prioridade aos problemas de condução e governabilidade e procura instrumentalizar a conduçấo de governo. Testa aponta e aprofunda as questões do poder, e Barrenechea e Trujillo formecem instrumentos para a execução de ações setoriais.

As três vertentes do enfoque estratégico do planejamento em saúde têm suas origens na discussão e crítica das metodologias e da compreensão do planejamento econômico normativo como instrumento para o desenvolvimento da América Latina; nas teorias de administração estratégica empresarial; na discussão e crítica da metodologia tradicional de planejamento em saúde. Essas origens estão imbricadas (o debate técnico-científico nảo se realiza isoladamente), diferenciando-se cada vertente, quanto à sua origem, apenas pela intensidade da influência de cada uma das discussōes.

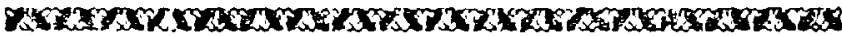

Following a brief historical review of economic and social planning in Latin America, the author presents

Cadernos de Saáde Pública, RJ, 7(1): 26-44, jan/mar, 1991. 
the origins of three tendencies in the strategic approach to health planning in: the debate over planning for Latin American development, the strategic business administration, and the discussion and critique of the CENDESIPAHO method of health planning.

\section{REFERÊNCIAS BIBLIOGRÁFICAS}

ANSOFF, H. Igor. Administração Estratégica. São Paulo, Ed. Atlas, 1983.

BARRENECHEA, Juan Jose \& TRUJILLO URIBE, Emiro. Salud para Todos en el año 2 .000. Implicaciones para la Planificacion y Administración de los Sistemas de Salud. Medellin, Un. Antioquia/OP S/OMS, 1987.

BOBBIO, N.; MATTEUCCI, N. \& PASQUINO, G. Dicionårio de Polftica. 2. ed. Brastlia, Ed, UNB, 1986.

BOURDIEU, Pierre. O Desencantamento do Mundo. Såo Paulo, Ed. Perspectiva, 1979.

CARDOSO DE MELO, Joảo Manoel. O capitalismo tardio. 3. ed. São Paulo, Ed. Brasiliense, 1984.

CARDOSO, Fernando Henrique. As idéias e seu lugar: ensaias sobre as teorias de desenvolvimento. Petropolis, Vozes, 1980.

GIORDANI, Jorge A. La planificación como proceso social, un esquema de análisis. Cuadernos Sociedad Venezuelana de Planificacion (3): 147-179, 1974.

KEYNES, John M.; KA LECKI, Michal. Os Pensadores. Sel. Textos. Paul Singer. Sâo Paulo, Abril Cultural, 1978.

MATUS, Carlos, Estrategia y Plan. 2. ed., México, Siglo XXI, 1978.

_. Planificación, Libertad y Conflicto. Cuadernos de IVEPLAN n: 1, Caracas, 1981.

- Polftica y Plan. Caracas, Ed. IVEPLAN, 1982.

OPS/OMS. Problemas Conceptuales y Metodológicos de la programacion de la Salud. Publicacion Cientffica $n: 111$, Washington, 1965.

- Hechos que revelan Progreso en Salud. Publicación Cientffica n: 227, Washington, 1971.

Plan Decenal de Salud para las Américas. Doc. Of. n: 13. Washington, 1973.

OPS/CPPS. Formulación de Pollticas de Salud. Santiago, 1975.

TESTA, Mario. Pensar en Salud. Buenos Aires, 1985. Mimeo.

- Pensamiento Estratégico, Lógica de Programacion, Estrategia y Programacion. Buenos Aires, 1986. Mimeo.

- Estrategia, Coherencia y Poder en las Propuestas de Salud - Parte II. Cuadernos Médico Sociales. Rosario (39) 3:28, 1987.

URIBE RIVERA, F. Javier. Os determinantes históricos do planejamento de saúde na América Latina. Dissertaçāo de Mestrado. IMS-UERJ, 1982. 